Jan N. Bremmer

\title{
Maidens, Magic and Martyrs in Early Christianity
}

\author{
Collected Essays I
}

[Maiden, Magie und Märtyrer im frühen Christentum. Gesammelte Aufsätze I.]

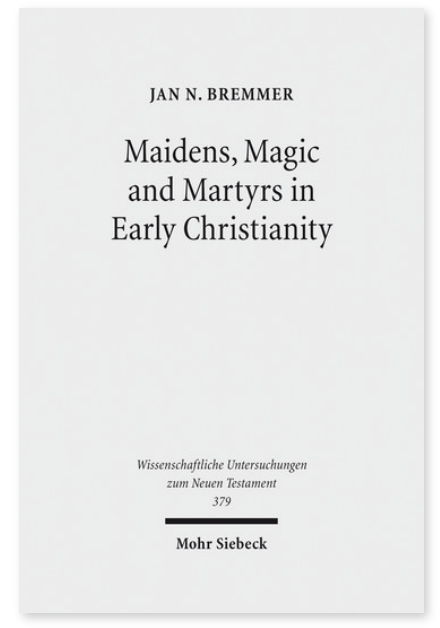

2017. XVIII, 501 Seiten. WUNT I 379

ISBN 978-3-16-155438-4

DOI 10.1628/978-3-16-155438-4

eBook PDF 194,00€

ISBN 978-3-16-154450-7

Leinen $194,00 €$
Veröffentlicht auf Englisch.

Warum nannten sich die frühen Anhänger Jesu 'Christen'? Was war ihr soziales und religiöses Kapital? Warum zog das Christentum sowohl arme Witwen als auch reiche Frauen an? Was hielten Heiden von den frühen Christen? Indem er die wichtigen, apokryphen Apostelgeschichten in die Untersuchung der Christentums und der antiken Welt mit einbezieht, veranschaulicht Jan N. Bremmer die Bedeutung von Frauen und den, oftmals überraschenden, Einsatz von Magie, während er auch für eine neue Datierung und Lokalisierung plädiert. Er zeigt auch, dass die frühchristlichen »tours of hell« sich sowohl an jüdische als auch an griechische Deutungsmuster anlehnen und im Laufe der Zeit zunehmend »christlich« werden. Der Autor schließt, indem er die faszinierenden Visionen in der Passion der Perpetua dadurch entschlüsselt, dass er sie in der heutigen Zeit verortet, und bringt den Leser dadurch dazu, mit den Hoffnungen und Ängsten der jungen christlichen Märtyrer mitzufühlen. Das genaue Augenmerk auf sowohl heidnischen als auch christlichen Traditionen macht diese Aufsätze, von denen alle aktualisiert und einige überarbeitet wurden, zu einer spannenden Lektüre für Wissenschaftler und fortgeschrittene Studenten.

Jan N. Bremmer Born 1944; 1979 PhD; 1978-90 Associate Professor for ancient history at the University of Utrecht; 1990-2009 Chair of Religious Studies at the Faculty of Theology and Religious Studies of the University of Groningen; 2019-20 Fellow at the Centre for Advanced Studies »Beyond Canon, « Regensburg.

https://orcid.org/0000-0001-8400-7143
Jetzt bestellen:

https://mohrsiebeck.com/buch/maidens-magic-and-martyrs-in-early-christianity-9783161554384?no_cache=1 order@mohrsiebeck.com

Telefon: +49 (0)7071-923-17

Telefax: $+49(0) 7071-51104$ 